\title{
Trends in premature mortality in the Islamic Republic of Iran: probability of dying between ages 30 and 70 years
}

Elaheh Kazemi, ${ }^{1}$ Ardeshir Khosravi, ${ }^{1}$ Saeide Aghamohamadi, ${ }^{1}$ Mohammad Shariati ${ }^{2}$ and Hossein Kazemeini ${ }^{1}$

${ }^{1}$ Center for Health Netwrok Management, Ministry of Health and Medical Education, Tehran, Islamic Republic of Iran (Correspondence to: Ardeshir Khosravi: ardeshir1344@yahoo.com). ${ }^{2}$ Department of Social Medicine, School of Medicine, Tehran University of Medical Sciences, Tehran, Islamic Republic of Iran.

\begin{abstract}
Background: The burden of noncommunicable diseases (NCDs) is a major challenge facing the whole world. Around 15 million premature deaths due to NCDs occur in people aged 30-70 years annually.

Aims: Mortality data based on death registration systems and population data were used to estimate proposed mortality statistics in the Islamic Republic of Iran.

Methods: Various criteria and methods were used to assess the quality of mortality data. The probability of dying among those aged 30-70 years for all causes and for NCDs was calculated using the life table method.

Results: The mortality rate in the population aged 30-69 years was 343.12 (per 100000 persons) in 2006 and decreased to 240.62 in 2016 in both sexes. The probability of dying due to NCDs was $21.36 \%$ in 2006 and declined to $14.95 \%$ in 2016 for both sexes.

Conclusions: The number of premature deaths due to NCDs have decreased over the last decade. We predict that this reduction will continue and the country will meet the targets of the WHO NCD action plan by 2025 and also the targets of the Sustainable Development Goals for reducing premature deaths by 2030. However, the morbidity and burden of NCDs are still public health concerns in the country. Due to advancements in health care technologies and also the aging population, these concerns will impose greater costs on the health system. Hence, prevention programmes for NCDs should be an urgent priority for Iranian health policy.
\end{abstract}

Keywords: probability of dying, mortality rate, vital statistics, noncommunicable diseases, Iran

Citation: Kazemi E; Khosravi A; Aghamohamadi S; Shariati M; Kazemeini H. Trends in premature mortality in the Islamic Republic of Iran: probability of dying between ages 30 and 70 years. East Mediterr Health J. 2021;27(1):33-40. https://doi.org/10.26719/emhj.20.067

Received: 04/05/19; accepted: 18/12/19

Copyright (C) World Health Organization (WHO) 2021. Open Access. Some rights reserved. This work is available under the CC BY-NC-SA 3.0 IGO license (https://creativecommons.org/licenses/by-nc-sa/3.o/igo).

\section{Introduction}

The burden of noncommunicable diseases (NCDs), including cardiovascular diseases (CVDs), cancers, diabetes and chronic respiratory diseases, is among the major challenges worldwide in the current century: NCDs accounted for $72.3 \%$ of deaths in 2016 (1). Around 15 million premature deaths due to NCDs in people aged 30-69 years occur every year worldwide (2). Remarkably, low-income and lower-middle-income countries with half of the premature NCDs deaths have more problems than developed countries. Additionally, within countries, poor people suffer more from NCDs.

This multidimensional health problem is determined by various factors such as low socioeconomic situation, international marketing, trade in health-harming products, urbanization, demographic transition, and changes in lifestyle (3).

The Islamic Republic of Iran, a middle-income country, has faced considerable social, economic and demographical transitions over the past 4 decades. Although, general health outcomes have improved considerably, there was a significant and uniform shift from communicable, maternal, neonatal, and nutritional (CMMN) conditions to NCDs from 1990 to $2010(4,5)$.
It seems that the country will face a $35 \%$ increase in burden of disease and injury over the next 2 decades, mainly due to aging or demographic and epidemiological changes. In this regard, communicable diseases (except HIV/AIDS) will have less contribution and on the other hand NCDs will play a significant role $(6,7)$.

Shahraz et al. estimated the population health and burden of disease profile for the Islamic Republic of Iran among 20 countries in the region, from Afghanistan to Lebanon and Qatar, between 1990 and 2010 (4). They used classic global burden of disease metrics, and indicated the ranking of the countries. Overall health outcomes, life expectancy at birth and age-standardized death rate improved considerably in the Islamic Republic of Iran from 1990 to 2010. Additionally, the results showed that the burden of communicable, maternal, neonatal, and nutritional conditions sharply declined compared with that of NCDs. The Islamic Republic of Iran ranked 13th in health-adjusted life expectancy and 12th in agestandardized death rate.

In 2011, international agencies such as the UN and WHO targeted reducing premature deaths due to NCDs, and announced the list of all countries which were planning to control NCDs. According to this agenda, 
the target indicator is to decrease by $25 \%$ the probability of dying due to 4 NCDs (CVD, diabetes, cancer, and chronic respiratory disease) in individuals aged 30-70 years by $2025(8,9)$. In addition, in 2015 the UN General Assembly formally released the 2030 programme for the Sustainable Development Goals (SDGs), which incorporated an arrangement of 17 strong new global goals and 169 particular targets. The plan additionally incorporates reducing by $33 \%$ premature mortality due to NCDs from the current level (10).

The aim of this paper was to estimate the probability of dying between ages 30 and 69 years for all-cause mortality and for 4 NCDs from 2006 to 2016 in the Islamic Republic of Iran.

\section{Methodology}

\section{Data source}

We used mortality data based on death registration systems and population data in order to estimate proposed mortality statistics. The cause of death data were gathered from the Ministry of Health and Medical Education. We also used all-cause mortality data from the National Organization for Civil Registration for 2006-2016. As the data quality (considering cause of death from the National Organization for Civil Registration) was not acceptable, these data were only used to estimate total mortality statistics and also the completeness of the death registration system (11).

We obtained population data according to sex and 5-year age groups via the Statistical Center of Iran. These data (for 2006, 2011 and 2016) were based on census data; estimated data were used for intercensual years (2007-2010 and 2012-2015). The method for population projection was the cohort component method based on information on the structure of the population (12). The People software package was used; this required data and information on population structure, fertility, mortality, sex ratio and migration. These were obtained using various data sources and reports such as birth and death registries from the National Organization for Civil Registration, the Ministry of Health and Medical Education and the Statistical Center of Iran $(12,13)$.

\section{Statistical methods}

Various criteria and methods were used to assess the quality of mortality data. We reviewed the missing data for age and sex information. Unknown sex- and age-related deaths were redistributed among causesex-age groups. We reviewed the quality of information on cause of death. One of the key criteria for checking the data quality of cause of death is the proportion assigned to "ill-defined or non-specific codes", known as "misclassification" of cause of death $(14,15)$. We redistributed deaths in the category symptoms, signs and ill-defined conditions proportionally to all well-defined causes except injury (16).

In this study we defined cause of death codes based on the International Classification of Diseases
(ICD) system as: CVDs (ICD-10 codes Ioo-I99), cancers (ICD-10 codes Coo-C97), diabetes (ICD-10 codes E10-E14), and chronic respiratory disease (ICD-10 codes J30-J98) (17-20).

In order to estimate the unconditional probability of dying due to all causes and to NCDs between ages 30 and 69 years, the life table method was used. In the first step, we calculated age-specific death rates in 5-year age groups (e.g. 30-34, 65-69) (18,21).

${ }_{5} M_{x}=$ deaths among persons aged $\mathrm{x}$ to $\mathrm{x}+5$ during $\mathrm{a}$ given year/ population $\mathrm{x}$ to $\mathrm{x}+5$ at the mid-point of the same year

In the second step, we calculated probability of dying in each 5-year age range between 30 and 70 years.

$$
{ }_{5} \mathrm{q}_{\mathrm{x}}=5^{*} 5 \mathrm{Mx} / 1+\left(2 \cdot 5^{*} 5 \mathrm{Mx}\right)
$$

The above formula is derived from the assumption that deaths are linearly distributed throughout the year (18).

In the next step, we calculated probability of survival in each 5-year age group between 30 and 69 years.

$$
{ }_{5} \mathrm{p}_{\mathrm{x}}=1-{ }_{5} \mathrm{q}_{\mathrm{x}}
$$

And in the final step, we calculated the unconditional probability of dying from age 30 to 69 years.

$$
{ }_{40} \mathrm{q}_{30}=1-\Pi 60{ }_{5} \mathrm{p}_{\mathrm{x}}
$$

\section{Correction for underreporting of deaths}

Generally, data from death registration systems have the drawback of underreporting. To correct for this limitation, various statistical and demographical methods have been developed. We used the new method presented by Adair and Lopez, which is based on the mixed effects model for predicting completeness of data from death registration system (22). The model for predicting completeness is based on the relationship between registered crude death rate (Reg CDR), the true level of child mortality rate $\left({ }_{5} q_{0}\right)$, registered child mortality rate $\left(\operatorname{Reg} \mathrm{q}_{0}\right)$, and population age structure (percentage of population 65 years old and above (\%Pop 65i). Data on the registered crude death rate were obtained from the National Organization for Civil Registration. We also used child mortality data estimated from the UN Inter-agency Group as the true level of child mortality $(22,23)$. The models are:

$$
\begin{aligned}
\operatorname{logit}\left(C_{i}^{A l l}\right)= & \beta_{0}+\operatorname{RegCDR} R_{i}^{2} * \beta_{1}+\operatorname{RegCDR} R_{i} * \beta_{2} \\
& +\% P o p 65_{i} * \beta_{3}+\ln (5 q 0)_{i} * \beta_{4} \\
& +C_{i}^{5 q 0} * \beta_{5}+\text { Year } * \beta_{6}+e_{i}+\gamma
\end{aligned}
$$


Completeness of Registration of All ages

$C_{i}^{5 q 0}=\frac{R e g 5 q 0}{5 q 0} \mid$

Completeness of Registration of ${ }_{5} \mathrm{q}_{0}$

In the above model $e$, is an error term, $i$ is calendar year, and $\gamma$ is a random effect and $\beta_{0}$ to $\beta_{6}$ are the coefficient. In the study by Adair and Lopez, all random effects of countries were presented in the appendices (22). We also had personal communication with them and they sent us an Excel template which contained all model coefficients (Adair T, personal communication, 15 August 2018).

\section{Average annual rate of decline}

As probability of dying from age 30 to age 70 years $\left({ }_{40} q_{30}\right)$ was estimated for each year during 2006 to 2016 , we next estimated the average annual rate of decline applying regressing log probability of death for each year:

$$
\ln \left({ }_{40} q_{30}\right)=a+b^{*} \text { year }
$$

This generated a coefficient (b) separately for males, females and both sexes, from which we calculated the relative decline as follows:

Annual average change ${ }_{40} q_{30}=1-e^{b}$

We can use this annual average change in $40^{9} 30$ to compare the mortality risk of 4 NCDs between men and women on the same basis (18). We also predicted the trends for probability of dying for each year over the period 2017-2025. To do this, using the parameters obtained from Model [6], the trend for probability of dying was predicted.

\section{Results}

In 2006, about 129668 (46.5\%) deaths occurred in people aged 30-69 years in the Islamic Republic of Iran. This increased to 137267 deaths in 2016.

Table 1 shows the proportion of adult deaths (30-69 years) due to NCDs for each sex during 2006-2016. In general, the proportion of NCD deaths was greater in females than in males. In 2006, these proportions were $75.92 \%$ and $60.88 \%$ respectively, and $74.73 \%$ and $65.69 \%$ respectively in 2016 .

The trend in the mortality rate for people aged 30-70 years during 2006-2016 is shown in Table 2. Overall, the rates for males are nearly double the rates for females over this period. The all-cause mortality rates per 100000 for males and females were 673.47 and 371.47 in 2006; these decreased to 450.69 and 263.56 in 2016. All-cause mortality rates per 100000 population were 518.39 in 2006 and 348.82 in 2016 for both sexes. It can be seen that mortality rates due to NCDs were higher in males than in females and also that they decreased considerably over the study period. The NCD mortality rates per 100000 population were 410.01 for males and 282.01 for females in 2006 , decreasing to 296.04 and 196.97 respectively in 2016. These rates were 343.12 in 2006 and 240.62 in 2016 for both sexes.

\begin{tabular}{|c|c|c|c|}
\hline \multirow[t]{2}{*}{ Year } & \multicolumn{3}{|c|}{ Sex } \\
\hline & Male (\%) & Female (\%) & Both (\%) \\
\hline 2006 & 60.88 & 75.92 & 66.17 \\
\hline 2007 & 63.12 & 77.32 & 68.29 \\
\hline 2008 & 62.07 & 76.78 & 67.48 \\
\hline 2009 & 62.57 & 75.44 & 67.22 \\
\hline 2010 & 61.81 & 76.67 & 67.15 \\
\hline 2011 & 63.94 & 76.76 & 68.69 \\
\hline 2012 & 65.13 & 76.39 & 69.25 \\
\hline 2013 & 65.49 & 75.40 & 69.13 \\
\hline 2014 & 69.60 & 76.66 & 72.19 \\
\hline 2015 & 67.12 & 76.57 & 70.55 \\
\hline 2016 & 65.69 & 74.73 & 68.98 \\
\hline
\end{tabular}

Table 3 shows the 2 most important mortality statistics: the probability of dying due to all causes and the probability of dying due to NCDs in individuals aged 30-69 years. Both indicators were higher in males than females; all indicators decreased over the study period. The probability of all-causes death was $33.28 \%$ and $22.27 \%$ for males and females respectively in 2006, declining to $24.38 \%$ and $15.63 \%$ respectively in 2016 . The probability of dying was $27.75 \%$ in 2006 and decreased to $19.61 \%$ in 2016 for both sexes. The probability of dying due to NCDs was $24.63 \%$ and $18.35 \%$ in 2006 and fell to $18.24 \%$ and $12.39 \%$ in 2016 for males and females respectively. This index was $21.36 \%$ in 2006 and fell to $14.95 \%$ in 2016 for both sexes.

Next, we calculated the average annual rate of decline of $40^{9} 30$ over the period 2006-2016 using a re-creation model of $\ln 409_{30}$. Regression analysis showed that the annual average rate of decline of $409_{30}$ for males in this period was $2.8 \%$ for all causes (Table 4 ). The annual average rate of decline of $40 \mathrm{q}_{30}$ for females in this period was 3.4\% based on Ministry of Health and Medical Education data for all causes. The annual average rate of decline of ${ }_{40} q_{30}$ for both sexes in this period was 3.3\% based on Ministry of Health and Medical Education data for all causes. The annual average rate of decline of ${ }_{40} 9_{30}$ for males over this period was $2.3 \%$ considering the 4 main NCDs as cause of death (using Ministry of Health and Medical Education data). This value was 3.7\% for females considering the 4 main NCDs as cause of death (using Ministry of Health and Medical Education data). The annual average rate of decline of $40 q_{30}$ for both sexes over this period was $3.2 \%$ considering the 4 main NCDs as cause of death (using Ministry of Health and Medical Education data). Table 4 shows the predictor variables of the regression model for predication annual average reduction such as regression coefficient, $F$-ratio, $P$-value, and $R^{2}$. All predictor variables were statistically significant $(P<0.05)$. 


\begin{tabular}{|c|c|c|c|c|c|c|}
\hline \multirow[t]{2}{*}{ Year } & \multicolumn{3}{|c|}{ All causes of mortality (No. per 100 000) } & \multicolumn{3}{|c|}{ NCD mortality (No. per 100 000) } \\
\hline & Male & Female & Total & Male & Female & Total \\
\hline 2006 & 673.47 & 371.47 & 518.39 & 410.01 & 282.01 & 343.12 \\
\hline 2007 & 590.09 & 342.82 & 464.99 & 372.48 & 265.07 & 317.56 \\
\hline 2008 & 592.33 & 339.54 & 459.89 & 367.63 & 260.70 & 310.32 \\
\hline 2009 & 581.80 & 332.00 & 453.45 & 364.05 & 250.47 & 304.82 \\
\hline 2010 & 563.74 & 313.69 & 435.69 & 348.46 & 240.52 & 292.58 \\
\hline 2011 & 524.16 & 311.50 & 418.49 & 335.13 & 239.11 & 287.46 \\
\hline 2012 & 501.58 & 296.25 & 395.80 & 326.66 & 226.31 & 274.10 \\
\hline 2013 & 482.53 & 283.13 & 377.59 & 315.99 & 213.48 & 261.04 \\
\hline 2014 & 481.45 & 284.07 & 370.45 & 335.08 & 217.78 & 267.42 \\
\hline 2015 & 463.23 & 268.24 & 355.96 & 310.92 & 205.39 & 251.12 \\
\hline 2016 & 450.69 & 263.56 & 348.82 & 296.04 & 196.97 & 240.62 \\
\hline
\end{tabular}

Figure 1 shows the trends for the probability of dying due to NCDs in the population aged 30-69 years for both sexes using observed data (2006-2016) and predicated data (2006-2025). From the observed data, which were corrected for underreporting and misclassification, the probability of dying from NCDs for both sexes declined from $21.36 \%$ in 2006 to $14.95 \%$ in 2016 . From the predicted model, this indicator was $21.23 \%$ in 2006 and is estimated to fall to $11.4 \%$ in 2025 .

\section{Discussion}

Our results showed that mortality due to the 4 leading NCDs was a public health concern in the Islamic Republic of Iran over the last decade. Total deaths due to NCDs increased in the Iranian population aged 30-69 years from 69072 in 2006 to 90281 in 2016. Although the total number of deaths increased, the unconditional probability of dying due to NCDs in this age group decreased from $21.3 \%$ in 2006 to $14.95 \%$ in 2016 ; we predicted that it would

\begin{tabular}{|c|c|c|c|c|c|c|}
\hline \multirow[t]{2}{*}{ Year } & \multicolumn{3}{|c|}{ All causes of death } & \multicolumn{3}{|c|}{4 main NCDs as cause of death } \\
\hline & Male (\%) & Female (\%) & Total (\%) & Male (\%) & Female (\%) & Total (\%) \\
\hline 2006 & 33.28 & 22.27 & 27.75 & 24.63 & 18.35 & 21.36 \\
\hline 2007 & 30.31 & 20.84 & 25.60 & 22.91 & 17.37 & 20.07 \\
\hline 2008 & 30.65 & 20.71 & 25.49 & 22.98 & 17.18 & 19.86 \\
\hline 2009 & 30.49 & 20.05 & 25.19 & 22.78 & 16.38 & 19.43 \\
\hline 2010 & 29.67 & 19.09 & 24.31 & 22.14 & 15.75 & 18.81 \\
\hline 2011 & 27.91 & 18.62 & 23.31 & 21.16 & 15.34 & 18.22 \\
\hline 2012 & 27.08 & 17.67 & 22.22 & 20.65 & 14.44 & 17.35 \\
\hline 2013 & 26.44 & 17.03 & 21.46 & 20.09 & 13.76 & 16.65 \\
\hline 2014 & 26.20 & 16.97 & 20.96 & 20.56 & 13.80 & 16.61 \\
\hline 2015 & 25.22 & 15.85 & 20.05 & 19.22 & 12.87 & 15.60 \\
\hline 2016 & 24.38 & 15.63 & 19.61 & 18.24 & 12.39 & 14.95 \\
\hline
\end{tabular}




\begin{tabular}{|c|c|c|c|c|c|c|}
\hline Cause of death & Alpha & Beta & 1-exp (Beta) & $\mathbf{F}$ & P-value & $\mathbf{R}^{2}$ \\
\hline \multicolumn{7}{|l|}{ All causes } \\
\hline Male & 42.979 & -0.029 & 0.028 & 217.445 & $<0.05$ & 0.96 \\
\hline Female & 51.795 & -0.035 & 0.034 & 742.592 & $<0.05$ & 0.988 \\
\hline Total & 50.031 & -0.034 & 0.033 & 525.541 & $<0.05$ & 0.983 \\
\hline \multicolumn{7}{|l|}{4 main NCDs } \\
\hline Male & 36.786 & -0.024 & 0.023 & 123.325 & $<0.05$ & 0.939 \\
\hline Female & 55.922 & -0.038 & 0.037 & 617.047 & $<0.05$ & 0.987 \\
\hline Total & 48.42 & -0.033 & 0.032 & 452.049 & $<0.05$ & 0.983 \\
\hline
\end{tabular}

\section{fall to $11.40 \%$ in 2025 .}

This paper is the first comprehensive attempt to estimate different statistics for premature deaths based on various data available in the country. Usually, data from death registration systems have 2 limitations: underreporting and misclassification. There are various indirect demographic methods, such as the death distribution method, which can be used to correct mortality data for underreporting (22). Using these methods requires 2 assumptions: a stable population and closed to migration. In light of the demographic changes in the Islamic Republic of Iran over the last 4 decades, we therefore used new methods in order to correct underreporting of deaths. Misclassification is another challenge considering data on cause of death based on registration. We used the distribution method to correct ill-defined or non-specific codes for cause of death.

We found that the probability of dying due to 4 main groups of NCDs in the Iranian population aged 30-69 years decreased during 2006-2016. From WHO estimates, the probability of dying from NCDs was $17.3 \%$ in 2012 , decreasing to $14.8 \%$ in 2015 ; this result is similar to our findings $(24,25)$.
Our findings also showed that, excepting the premature death rate from diabetes, which increased (11.0 per 100000 in 2006 and 16.7 in 2016), death rates from the other 3 NCDs (cancer, CVD and chronic respiratory disease) decreased between 2006 and 2016. These patterns of reduction for 3 groups of diseases and increasing for diabetes were noted in the WHO report and also the Global Burden of Disease study $(26,27)$. In addition, incidences of these 4 diseases were 171.7 for cancer, 877.0 for CVDs, 450 for diabetes and 486 for chronic respiratory disease per 100000 in 2006 and 210.6 for cancer, 879.3 for CVDs, 594.7 for diabetes and 505.3 for chronic respiratory disease per 100000 in 2016. Hence, the incidence of CVDs did not increase considerably over the study period. However, morbidity and mortality increased for diabetes. This could be the result of socioeconomic and lifestyle changes in the Islamic Republic of Iran over the past 2 decades.

Among the 4 groups of diseases, CVD had the highest mortality rate, and as a result, this showed the greatest decrease during the study period. Therefore, CVD might have been responsible for the greatest contribution to reducing the probability of death (mortality) from NCDs.

Figure 1 Trends in probability of dying (\%) due to noncommunicable diseases in the population aged 30-69 years based on observed and predicated data, Islamic Republic of Iran, 2006-2025

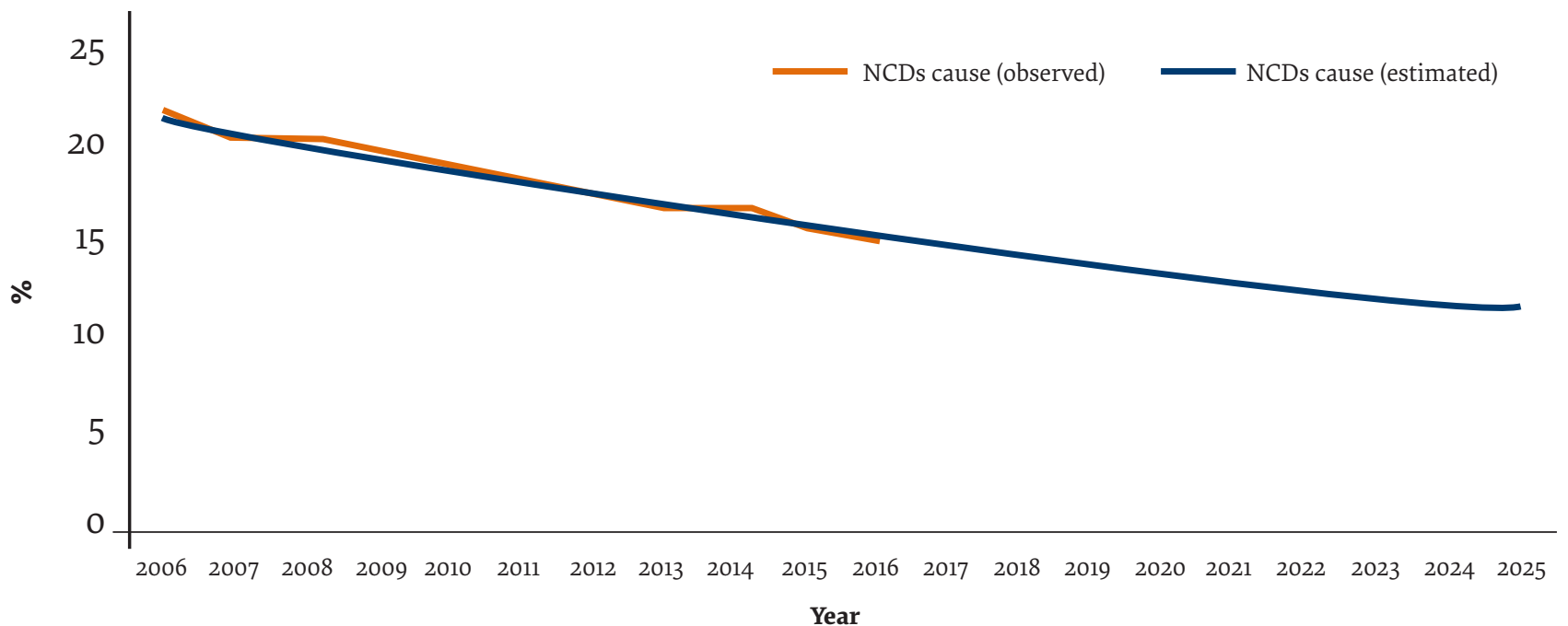


Considering the significant improvements in access and continuous improvements in diagnosis and treatment of CVDs, the case-fatality for CVDs has decreased significantly (28).

According to a WHO report, at least $80 \%$ of premature heart disease, stroke and type 2 diabetes, and $40 \%$ of cancers can be prevented through interventions aimed at several risk factors, such as healthy diet, regular physical activity and avoidance of tobacco products (29).

In the context of international attempts, including the improvement of health service delivery based on universal health coverage, a memorandum of understanding was signed in 2015 between the Ministry of Health and Medical Education and other relevant ministries (aimed at the prevention and control of NCDs) (7,30). This document was planned to implement various programmes to prevent NCDs and related risk factors by 2025. Additionally, to provide universal health coverage, the Ministry of Health and Medical Education launched a transformation plan in 2014. Service packages delivered in the primary health care units were revised based on the WHO Package of Essential Noncommunicable Disease Interventions (known as IrPEN); these packages are currently available at primary health care units $(31,32)$.

The information system for mortality and cause of death is a key component in monitoring and assessment of health interventions to prevent and reduce the NCDs and related risk factors. During the last decade, the cause of death registration system was improved in the
Islamic Republic of Iran (24). Using multiple data sources for capturing cause of death information increased the completeness of the data. Using the detailed ICD-10 coding system has also improved the quality of cause of death data, particularly for females. An urgent priority for public health policy is focusing on better diagnosis of cause of death through the issuing of death certificates by physicians of adult mortality.

Although we attempted a comprehensive assessment of trends and levels of premature death due to NCDs, this research had several limitations. First, mortality data for 2 provinces (Tehran until 2014 and Isfahan 2007-2010) were not available in Ministry of Health and Medical Education data; thus, we assumed that their patterns for cause of death were the average of all other provinces. Second, the Statistical Center of Iran estimated population data for age and sex were used for the intercensual years. Third, in this study we corrected the cause of death data for garbage and ill-defined codes using a simple proportional distribution method.

In conclusion, premature deaths due to NCDs have decreased over the last decade in the Islamic Republic of Iran. We predicted that this reduction would continue and that the country will meet the targets of the WHO NCD action plan for 2025 and also the SDGs targets to reduce premature deaths by 2030 . The improvements in curative services along with the aging population will impose more costs on the health system. Hence, a prevention programme for NCDs should be an urgent priority in Iranian health policy $(29,33)$.

\section{Acknowledgement}

The authors would like to thank Tim Adair and Alan D Lopez from the University of Melbourne for sharing their information and file. We are also grateful for their comments and consults.

Funding: None.

Competing interests: None declared.

\section{Tendances en matière de mortalité prématurée en République islamique d'Iran : probabilité de décès entre 30 et 70 ans}

\section{Résumé}

Contexte : La charge des maladies non transmissibles (MNT) constitue un défi majeur pour le monde entier. Chaque année, près de 15 millions de décès prématurés dus à des maladies non transmissibles se produisent chez des personnes âgées entre 30 et 70 ans.

Objectifs : Des données sur la mortalité fondées sur les systèmes d'enregistrement des décès et des données obtenues en population ont été utilisées pour estimer les statistiques de mortalité proposées en République islamique d'Iran.

Méthodes : Divers critères et méthodes ont été utilisés pour évaluer la qualité des données sur la mortalité. La probabilité de décès parmi les 30-70 ans, toutes causes confondues et pour les maladies non transmissibles, a été calculée à l'aide de la méthode de la courbe de survie.

Résultats : Le taux de mortalité dans la population âgée de 30 à 69 ans était de 343,12 (pour 100000 personnes) en 2006 et a régressé à 240,62 en 2016 pour les deux sexes. La probabilité de décéder des suites de maladies non transmissibles était de $21,36 \%$ en 2006 et a diminué pour atteindre $14,95 \%$ en 2016 pour les deux sexes.

Conclusions: Le nombre de décès prématurés dus aux MNT a diminué au cours de la dernière décennie. Nous prévoyons que cette baisse se poursuivra et que le pays atteindra les cibles du plan d'action de l'OMS pour la lutte contre les maladies non transmissibles à l'horizon 2025 ainsi que les cibles des objectifs de développement durable visant à réduire les décès prématurés d'ici 2030. Toutefois, la morbidité et le fardeau des MNT continuent à être une source de 
préoccupation pour la santé publique dans le pays. En raison des progrès des technologies en matière de soins de santé et de vieillissement de la population, ces préoccupations entraîneront des coûts plus élevés pour le système de santé. Les programmes de prévention des maladies non transmissibles devraient donc constituer une priorité urgente de la politique de santé iranienne.

$$
\text { الهاهات كاظمى، الودشير خسروى، سعيده آغا محمدي، المبكرة في جمهورية إيران الإسلامية: احتمال الوفاة بين } 30 \text { و } 70 \text { عاماً }
$$

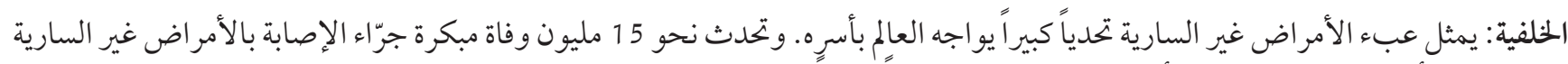

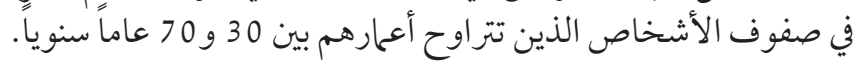

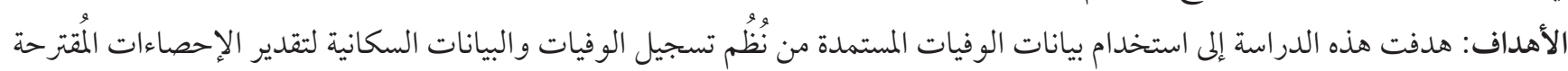
للوفيات في جمهورية إير ان الإسلامية.

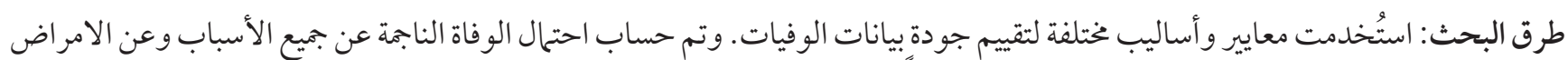

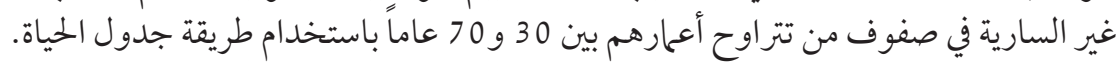

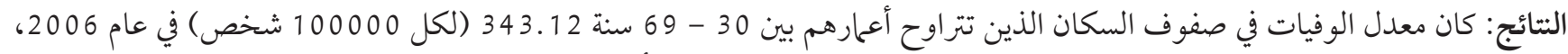

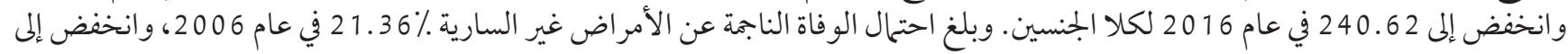

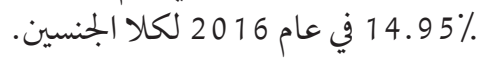

الاستنتاجات: انخفض عدد الوفيات المبكرة الناجمة عن الأمراض غير السارية على مدار العقد الماضي. ونتنبأ باستمرار هذا الانخفاض، إض وسيفي

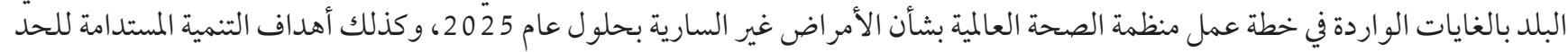

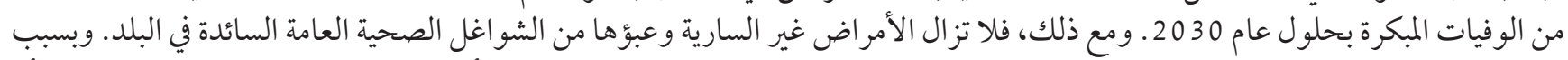

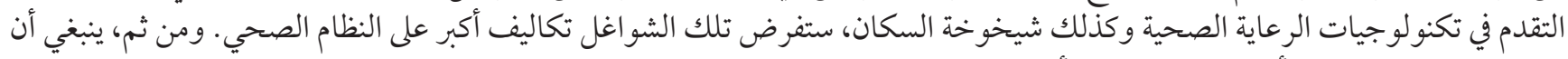

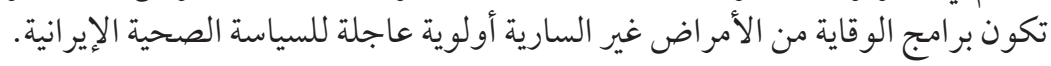

\section{References}

1. Christopher J L Murray. Global, regional, and national age-sex specific mortality for 264 causes of death, 1980-2016 : a systematic analysis for the Global Burden of Disease Study 2016. Lancet. 2017 Sep 16;390:(10100):1151-210. doi:10.1016/S0140-6736(17)32152-9

2. Ezzati PM. NCD Countdown 2030 : worldwide trends in non-communicable disease mortality and progress towards Sustainable Development Goal target 3.4. Lancet. 2018 Sep 22;392(10152):1072-88. doi:10.1016/So140-6736(18)31992-5

3. NCDs progress monitor 2017. Geneva: World Health Organization; 2017.

4. Naghavi M, Shahraz S, Sepanlou SG, Dicker D, Naghavi P, Pourmalek F, et al. Health transition in Iran toward chronic diseases based on results of global burden of disease 2010. Arch Iran Med. 2014;17(5):321-35.

5. Sepanlou SG, Farin Kamangar, Hossein Poustchi RM. Reducing the burden of chronic diseases: a neglected agenda in Iranian health care system, requiring a plan for action. Arch Iran Med. 2010;13(4):340-50.

6. Khajehkazemi R, Sadeghirad B, Karamouzian M, Fallah M. The projection of burden of disease in Islamic Republic of Iran to 2025. PLoS One. 2013 Oct 17;8(10):e76881. doi:10.1371/journal.pone.0076881

7. Peykari N, Hashemi H, Dinarvand R, Haji-aghajani M, Malekzadeh R. National action plan for non-communicable diseases prevention and control in Iran ; a response to emerging epidemic. J Diabetes Metab Disord. 2017 Jan 23;16:3. doi:10.1186/s40200017-0288-4

8. Kontis V, Mathers CD, Rehm J, Stevens GA, Shield KD, Bonita R, et al. Contribution of six risk factors to achieving the $25 \times$ 25 non-communicable disease mortality reduction target : a modelling study. Lancet Glob Health. 2015 Dec;3(12):e746-57. doi:10.1016/S2214-109X(15)00179-5

9. Fact sheets on sustainable development goals: health targets. Noncommunicable diseases. copenhagen: World Health Organization Regional Office for Europe; 2017 (http://www.euro.who.int/_data/assets/pdf_file/0007/350278/Fact-sheet-SDG-NCD-FINAL-25-10-17.pdf, accessed 22 April 2020).

10. The sustainable development agenda. New York: United Nations, Sustainable Development Goals; 2019:1-4 (https://www.un.org/ sustainabledevelopment/development-agenda/, accessed 22 April 2020).

11. Khosravi A, Taylor R, Naghavi M, Lopez AD. Mortality in the Islamic Republic of Iran , 1964-2004. Bull World Health Organ. 2007 Aug;85(8):607-14. doi:10.2471/blt.06.038802 
12. Population and housing censuses. Tehran: Statistical Center of Iran; 2016 (https://www.amar.org.ir/english/Population-and-Housing-Censuses, accessed 22 April 2020).

13. Zanjani H. Projection population of Iran by rural and urban areas by 2041. J Iran Soc Dev Stud. 2016;8(3).

14. Joubert J, Rao C, Bradshaw D, Vos T, Lopez AD. Evaluating the quality of national mortality statistics from civil registration in South Africa, 1997-2007. PLoS One. 2013 May 27;8(5):e64592. doi:10.1371/journal.pone.0064592

15. Khosravi A, Rao C, Naghavi M, Taylor R, Jafari N, Lopez AD. Impact of misclassification on measures of cardiovascular disease mortality in the Islamic Republic of Iran : a cross- sectional study. Bull World Health Organ. 2008 Sep;86(9):688-96. doi:10.2471/ blt.07.046532

16. WHO methods and data sources for country-level causes of death. Geneva: World Health Organization; 2018 (http://terrance. who.int/mediacentre/data/ghe/GlobalCOD_method_2000_2016.pdf?ua=1, accessed 22 April 2020).

17. Noncommunicable diseases global monitoring framework: indicator definitions and specifications. Geneva: World Health Organization; 2013 (https://www.who.int/nmh/ncd-tools/indicators/GMF_Indicator_Definitions_Version_NOV2014.pdf, accessed 22 April 2020).

18. Kwana AK, Yuen-hoa L, NGa E, Chingaa R. Application of life table method for measuring mortality risk of non-communicable diseases in Hong Kong [Internet]. Hong Kong: Centre for Health Protection, Department of Health; 2014 (https://nanopdf.com/ download/paper-iaos-2014-conference-5afc58aze3e99_pdf, accessed 22 April 2020).

19. A comprehensive global monitoring framework including indicators and a set of voluntary global targets for the prevention and control of NCDs. Geneva: World Health Organization; 2011:1-16.

20. A comprehensive global monitoring framework including indicators and a set of voluntary global targets for the prevention and control of NCDs. Geneva: World Health Organization; 2012:1-23.

21. Information on estimation methods global health observatory (GHO) data. Geneva: World Health Organization; 2016:30-2.

22. Adair T, Lopez AD. Estimating the completeness of death registration : an empirical method. PLoS One. 2018 May 30;13(5):e0197047. doi:10.1371/journal.pone.0197047

23. Child mortality estimates. New York: UNICEF, UN Inter-agency Group for Child Mortality estimation; 2017 (https://childmortality.org/data, accessed 22 April 2020).

24. World health statistics 2017: monitoring health for the SDGs. Geneva: World Health Organization; 2017 (https://www.who.int/ gho/publications/world_health_statistics/2017/en/, accessed 22 April 2020).

25. World health statistics 2016: monitoring health for the SDGs. Geneva: World Health Organization; 2016 (https://www.who.int/ gho/publications/world_health_statistics/2016/en/, accessed 22 April 2020).

26. Disease burden and mortality estimates. Cause-specific mortality, 2000-2016. Geneva: World Health Organization; 2019:2-4 (https://www.who.int/healthinfo/global_burden_disease/estimates/en/, accessed 22 April 2020).

27. Global Burden of Disease Collaborative Network. Global Burden of Disease Study 2017 (GBD 2017) results. Seattle: Institute for Health Metrics and Evaluation (IHME). 2019:2-3 (http://ghdx.healthdata.org/gbd-results-tool, accessed 22 April 2020).

28. Sarink D, Nedkoff L, Briffa T, Shaw E, Magliano DJ, Stevenson C, et al. Trends in age- and sex-specific prevalence and incidence of cardiovascular disease in Western Australia. Eur J Prev Cardiol. 2018;25(12):1280-90. doi:10.1177/2047487318786585

29. The impact of chronic disease in the Islamic Republic of Iran. Geneva: World Health Organization. 2002 (https://www.who.int/ chp/chronic_disease_report/media/impact/iran.pdf?ua=1, accessed 22 April 2020).

30. Hashemi H, Larijani B, Sayari AK, Malekzadeh R, Dinarvand R, Aghajani M, et al.. National action plan for prevention and control of NCDs and the related risk factors in the Islamic Republic of Iran, 2015 to 2025. Tehran: Ministry of Heath and Medical Education; 2015 (http://incdc.behdasht.gov.ir/uploads/sanadmelli_en.pdf, accessed 15 October 2019).

31. Hadizadeh A, Javadpour Nobandegani S NB. Familiarize with the main interventions of noncommunicable diseases in the primary health care system. Electronic J Shiraz Univ Medical Sci. (http://ejournal.sums.ac.ir/58/khandani/irapen1.html, accessed 20 October 2019).

32. Kusha A, Najmi M, Mahdavihazaveh AR, Moghisi AR, Motlagh A, Yarahmadi SH, et al. [Iranian package of essential non communicable disease]. Tehran: Ministry of Heath and Medical Education; 2017 (in Farsi) (http://baharestan.iums.ac.ir/files/baharestan/files/FixMohtava-Behvarz.pdf, accessed 22 April 2020).

33. Islamic Republic of Iran on a fast-track to beating noncommunicable diseases. World Health Organization. 2019:2-4 (https:// www.who.int/news-room/feature-stories/detail/islamic-republic-of-iran-on-a-fast-track-to-beating-noncommunicable-diseases, accessed 22 April 2020). 